\section{LEVTREND: A FORTRAN program for analyzing and displaying the results of repeated measures across multiple factors}

\author{
CHARLES NEURINGER \\ University of Kansas, Lawrence, Kansas 66045
}

LEVTREND is a FORTRAN program written to analyze and display in a ready-for-publication form the results of a $\mathrm{N}+1$ factor (either as levels or as groups) by $\mathrm{N}$ repeated-measures design. It uses a variable formatting technique that allows the user to either develop his own input data layout or use a free-form input format.

Input. The number of factors (levels or groups), the number of subjects in each factor, and the number of repeated measures are read in from a parameter card. The second input card is the data input format. The data are then read from data cards using the format described in the data format card.

Output. The output is displayed in two tables. Table 1 displays the marginal means and standard deviations for each level and repeated measure, as well as those for each $\mathrm{I}$ by $\mathrm{J}$ cell. Table 2 displays the analysis of variance summary table of the multiple-factor by repeated-measures design in a form that follows the American Psychological Association (1974) standards.

Capacity. LEVTREND is set up to handle up to 200 subjects dispersed among $\mathrm{N}+1$ groups, with each subject having up to 40 repeated measures. The program's capabilities may be enlarged by user alterations of the appropriate dimension statements. A minimum of $20 \mathrm{~K}$ words of memory is needed to load the program. Compiling time is less than $.0006 \mathrm{~h}$. Load and execution time varies depending on the amount of data.

Computer. LEVTREND may be used with a Honeywell 66/60, Honeywell 635, or any IBM computer that supports a WATFIV compiler.
Table 1

\begin{tabular}{llrrrrr}
\hline & & \multicolumn{4}{c}{ Measure } & \\
\cline { 3 - 6 } & & 1 & \multicolumn{1}{c}{2} & \multicolumn{1}{c}{3} & \multicolumn{1}{c}{4} & Total \\
\hline \multirow{2}{*}{ Group 1 } & Mean & 2.33 & 1.33 & 5.33 & 3.00 & 3.00 \\
& SD & 2.08 & 1.53 & .58 & 1.00 & 1.95 \\
Group 2 & Mean & 5.33 & 3.67 & 7.00 & 7.67 & 5.92 \\
& SD & 1.53 & 1.53 & 1.00 & 1.53 & 2.02 \\
Total & Mean & 3.83 & 2.50 & 6.17 & 5.33 & \\
& SD & 2.32 & 1.87 & 1.17 & 2.80 & \\
\hline
\end{tabular}

Table 2

Analysis of Variance Summary

\begin{tabular}{lrrrr}
\hline & \multicolumn{4}{c}{ Mean } \\
& Source & df & Square & \multicolumn{1}{c}{ F } \\
\hline Between Groups & 51.042 & 1 & 51.042 & 11.893 \\
Subjects & 17.167 & 4 & 4.292 & \\
Total Between Subjects & 68.208 & 5 & & \\
Between Measures & 47.458 & 3 & 15.819 & 12.798 \\
Groups by Measures & 7.458 & 3 & 2.486 & 2.011 \\
Pooled Subjects by Measures & 14.833 & 12 & 1.236 & \\
Total Within Measures & 69.750 & 18 & & \\
Total & 137.958 & 23 & & \\
\hline
\end{tabular}

Availability. A user's instruction manual, program listing, and FORTRAN deck for either the batch or a timesharing interactive version of LEVTREND may be obtained at no cost from Charles Neuringer, Department of Psychology, University of Kansas, Lawrence, Kansas 66045.

\section{REFERENCE}

American Psychological Assochation. Publication manual (2nd ed.). Washington, D.C: Author, 1974.

(Accepted for publication May 30, 1978.) 